\title{
Interpretation Bias in Online and Offline Social Environments and Associations with Social Anxiety, Peer Victimization, and Avoidance Behavior
}

\author{
Anne C. Miers ${ }^{1} \cdot$ Sindy R. Sumter ${ }^{2} \cdot$ David M. Clark $^{3} \cdot$ Eleanor Leigh $^{3}$
}

Published online: 8 April 2020

(c) The Author(s) 2020

\begin{abstract}
Background In face-to-face (offline) social situations a tendency, or bias, to negatively interpret ambiguous situations is consistently related to social anxiety. Although social interactions increasingly occur over the Internet (online), our understanding of cognitive processes in online social situations and how they relate to social anxiety, social experiences, and behavior, is limited.

Methods In a sample of 324 young people (18-25 years), the current study addressed this gap in two ways: by simultaneously investigating online and offline interpretation bias in relation to social anxiety; and examining the extent to which online interpretation bias predicts peer victimization and avoidance.

Results In line with hypotheses, online and offline interpretation bias each correlated positively with social anxiety; the offline interpretation bias-social anxiety association was stronger. Regression analyses revealed unique associations between online interpretation bias and online peer victimization and avoidance, after controlling for social anxiety and offline interpretation bias.

Discussion Findings suggest that cognitive behavioral interventions for social anxiety could be optimized through eliciting and testing negative social beliefs related to online social settings.

Conclusions The current study's results indicate the importance of studying online interpretation bias to further understand social anxiety in online social environments.
\end{abstract}

Keywords Avoidance behavior · Interpretation bias · Peer victimization · Online social situations $\cdot$ Social anxiety

Interpretation bias can be defined as a tendency to interpret, or assign meaning to, ambiguous stimuli in a consistent manner (Schoth and Liossi 2017). These stimuli include but are not limited to ambiguous audio cues, words, images, facial

Electronic supplementary material The online version of this article (https://doi.org/10.1007/s10608-020-10097-1) contains supplementary material, which is available to authorized users.

Anne C. Miers

acmiers@fsw.leidenuniv.nl

1 Unit Developmental and Educational Psychology, Institute of Psychology, Leiden University, Pieter de la Court Building, P.O. Box 9555, 2300 RB Leiden, The Netherlands

2 Amsterdam School of Communication Research (ASCoR), University of Amsterdam, Amsterdam, The Netherlands

3 Department of Experimental Psychology, University of Oxford, Oxford, UK expressions and social situations. Research has demonstrated an interpretation bias among different populations including individuals with depression, anorexia, chronic pain, and alcohol dependence (Schoth and Liossi 2017). For example, patients with a chronic illness are more likely to interpret ambiguous words as a word related to their pain or illness rather than a neutral word (Schoth and Liossi 2016).

An interpretation bias has also been explored in relation to social anxiety; in this context an interpretation bias is theorized to favor a negative or threatening interpretation of ambiguous social situations specifically (Heinrichs and Hofmann 2001; Stopa and Clark 2000), and is proposed to be a key maintenance mechanism in most cognitive-behavioral accounts of social anxiety (e.g., Clark and Wells 1995; Musa and Lepine 2000; Rapee and Heimberg 1997). In line with this, empirical studies have consistently found an association between interpretation bias and social anxiety (e.g., Amin et al. 1998; Leigh and Clark 2018; Stopa and Clark 
2000). However, these studies have been undertaken almost exclusively in relation to offline or face-to-face situations, and there is a paucity of research investigating interpretation bias and social anxiety in online situations. ${ }^{1}$ This is surprising given that, for most people in their late teens and early twenties, life without online communication has become unimaginable (Alt 2015). Young people can choose to communicate with others through a myriad of applications using their personal computer, laptop, tablet, or smartphone. Online communication has become an integral part of their social lives (Coyne et al. 2013) and the percentage of young people (18-29 years) using social media reached $90 \%$ in the US (Perrin 2015; social media defined as social networking sites like Facebook, Twitter, or LinkedIn) and $98.5 \%$ in The Netherlands (Kloosterman and van Beuningen 2015; social media including Facebook, WhatsApp, Instagram, Skype, and YouTube).

Social media platforms for screen-based communication have created a new type of social situation: one that is less rich in terms of the presence of nonverbal cues in comparison to offline social situations (Daft and Lengel 1986; Valkenburg et al. 2016; Walther 2011). Because nonverbal cues such as gestures, vocal intonation, or facial expression often provide information about the meaning of a statement, for example whether it is sarcastic or serious, the lack of these features in text-based screen communication may create greater ambiguity (Kruger et al. 2005; Riordan and Kreuz 2010). Furthermore, the visual anonymity (Joinson 2001) of online communication may facilitate impulsive reactions (Valkenburg and Peter 2011) that without, or with limited, visual and auditory cues could be particularly ambiguous. For instance, a one letter, quick response like "K" (i.e., short for ' $\mathrm{OK}$ ') to an invitation to see a movie, might be attributed by the recipient to a lack of enthusiasm to meet up rather than the sender not having enough time to write a full reply. Likewise, whilst the accessibility of the Internet allows for abundant interaction possibilities with family members, friends, and like-minded peers, it also vastly increases the number of potential ambiguous messages to which a young person may be exposed.

To date there is only limited evidence to support the hypothesis that social anxiety is positively related to a tendency to negatively interpret online social situations. First, in a study by Kingsbury and Coplan (2016), who examined the

\footnotetext{
${ }^{1}$ In this paper, the terms online and offline refer exclusively to computer mediated interactions (e.g., communication via internet or smartphone applications) and face-to-face interactions, respectively. We note here that the terms online and offline have a different meaning in interpretation bias research, namely that online measures record a person's initial interpretation, and offline measures are defined as allowing time to contemplate the ambiguous stimuli (Schoth and Liossi 2017).
}

association between interpretation bias and social anxiety in text messages in a sample of 215 university undergraduates, participants were presented with a screen image of a hypothetical and ambiguous text message received from a friend (e.g., 'I heard about last night'). Following each vignette, the participants had to rate the likelihood of two interpretations coming to mind, one benign and one negative, with higher scores reflecting a greater likelihood that the interpretation would come to mind. The authors reported a small but significant positive correlation between interpretation bias and social anxiety $(r=0.14)$. A second study (Carruthers et al. 2019) asked a group of high and low socially anxious students (18-25 years) to imagine hypothetical ambiguous Facebook scenarios with a risk of negative evaluation happening to them (e.g., "Somebody leaves a jokey comment on one of your entries on FB") and to rank order the likelihood of a negative and two neutral interpretations. High socially anxious students interpreted the scenarios significantly more negatively than low socially anxious students. The effect size for this anxiety group difference was large $(d=1.38)$. Taken together, these two studies (Carruthers et al. 2019; Kingsbury and Coplan 2016) suggest that social anxiety is associated with negative interpretations of ambiguous online social situations.

However, an alternative perspective is that online settings are actually lower in threat. Specifically, according to the hyperpersonal model of computer-mediated communication (Walther 2011) the reduced nonverbal cues in online settings make it likely that the receivers of messages will fill in the missing information in a favorable way. This theory implies that young people are less inclined to interpret incomplete (and likely ambiguous) messages received within the social media context in a negative manner compared to offline situations. In line with this assumption Lee and Stapinski (2012) showed that socially anxious adults reported less negative expectations regarding a hypothetical online interaction with an acquaintance compared to a similar offline interaction. Participants were asked to estimate the likelihood of negative evaluation by the interaction partner such as judging the conversation as boring. Participants with higher social anxiety levels perceived the probability of negative evaluation as less likely in the online versus offline situations. Moreover, Weidman et al. (2012) found that young people higher in self-reported social anxiety reported greater feelings of comfort and reduced social pressure in online compared to offline situations. A consequence of experiencing the online context as less-threatening could be a reduced tendency to assign negative interpretations to ambiguous online social events.

Research shows that social anxiety is associated with a host of interpersonal difficulties across the lifespan (Alden and Taylor 2004). Young people with social anxiety avoid social situations, have fewer friends, fewer romantic 
partners, and the relationships they do have are typically less intimate than nonsocially anxious peers (Alden and Taylor 2004; Leigh and Clark 2018; Miers et al. 2014). They are also more likely to be subjected to peer victimization (Siegel et al. 2009). One mechanism that might explain the association between social anxiety and these social experiences and behavior is an interpretation bias. The tendency to attribute negative meaning to ambiguous social situations, such as the perception that a conversational partner who yawns during a conversation is doing so because he or she thinks you are boring, may motivate overt avoidance of similar social situations or the use of covert in-situation avoidance safety behaviors (e.g., avoiding talking about the self, keeping body movement to a minimum to avoid attracting attention) to prevent or mitigate social rejection (Gray et al. 2019). With regard to the association between social anxiety and peer victimization, it has been proposed that negative interpretation of social situations by socially anxious individuals may lead to perceived hostile actions in others and, in turn, elicit actual negative behavior and victimization from other people, possibly due to changes in the socially anxious person's behavior (Gros et al. 2010; Siegel et al. 2009).

A few studies have investigated relations between social anxiety, peer victimization, social avoidance and interpretation bias related constructs, such as attributions (Hoglund and Leadbeater 2007; Perren et al. 2013; Prinstein et al. 2005), however to our knowledge no study has specifically tested the hypothesis that interpretation bias may partly explain why socially anxious youth are victimized by their peers and avoid social situations. Whilst these associations and the hypothesized mediation pathway have been examined or proposed in relation to offline interactions, we would expect to observe a similar pattern of associations amongst social anxiety, online interpretation bias, and online interpersonal difficulties. For example, it has been found that, in general, there is great similarity between individuals' online and offline environments (Gosling et al. 2008). For socially anxious individuals specifically, Weidman and Levinson (2015) showed that their offline relationship impairment (i.e., social inactivity, poor relationship quality, and difficulty self-disclosing) carries over into online contexts and can be readily observed by others such as having few friends on a Facebook profile. Similarly, there is considerable overlap between people's online and offline peer networks and offline victimization is strongly related to online victimization (Gini et al. 2018). A longitudinal study of Dutch adolescents by van den Eijnden et al. (2014) demonstrated that although only offline victimization worsened social anxiety, social anxiety predicted an increase in online as well as offline victimization. Hence, these reported similarities between socially anxious individuals' online and offline social experiences and behavior tentatively suggest that an interpretation bias could be a mechanism in the online social context too.

\section{The Current Study}

In sum, although it is clear that young people's social lives increasingly take place in the online as well as the offline environment, our understanding of cognitive processes in online social situations and their relevance for understanding social anxiety and associated social experiences and behavior is limited. In response to this, the goals of this study were twofold: to simultaneously examine whether, in the same sample of young people, an online and offline interpretation bias (i.e., self-reported cognitive perceptions of, respectively, ambiguous hypothetical online and offline social situations) explain individual differences in social anxiety, and, to investigate whether online and offline interpretation biases explain individual differences in peer victimization and avoidance behavior within-context, whilst accounting for social anxiety. That is, do interpretation biases in an online and offline social context show within-context specific associations, such that online interpretation bias more strongly contributes to online peer victimization and avoidance than an offline interpretation bias, and vice-versa, an offline interpretation bias contributes more strongly than an online interpretation bias to peer victimization in and avoidance of face-to-face situations?

A better understanding of how online social situations are interpreted by socially anxious people is important because it may help to extend and improve current interventions by targeting cognitive biases in the online, as well as the offline, social context (Leigh and Clark 2018; McLellan et al. 2015). We therefore included parallel measures of online and offline interpretation bias, peer victimization, and avoidance behavior. We chose to study young adults in the age range 18-25 years because for the overwhelming majority of this age group online communication is a core part of their interactions with others, and social anxiety levels are stable at this age (Miers et al. 2013). In addition, research in this area to date has predominantly focused on this young adult age group (Prizant-Passal et al. 2016), allowing for relevant comparisons with previous studies.

We tested three research questions: (a) How is an online interpretation bias related to social anxiety and does it contribute unique variance in social anxiety over and above that of an offline interpretation bias?; (b) Does an online interpretation bias uniquely contribute to peer victimization and avoidance in the online context, over and above social anxiety?; and (c) Does an offline interpretation bias uniquely contribute to peer victimization and avoidance behavior in an offline context, over and above social anxiety? In addition, we explored the role of interpretation bias 
as an explanatory, or mediating, variable in the relationships between social anxiety and peer victimization and avoidance behavior, in both online and offline social environments.

We hypothesized that online interpretation bias is significantly positively related to social anxiety (Carruthers et al. 2019; Kingsbury and Coplan 2016) and tentatively expected it to account for unique variance over and above offline interpretation bias. In relation to research question (b), because social anxiety and online peer victimization are only weakly related (Dempsey et al. 2009) we expected online interpretation bias to make a unique contribution to online peer victimization. Given the lack of research investigating social anxiety and avoidance of online social situations we could not formulate expectations for this particular construct. In relation to research question (c), we hypothesized that offline interpretation bias would make a unique contribution to peer victimization (Siegel et al. 2009), and, drawing from its proposed role in the maintenance of social anxiety (Clark and Wells 1995; Musa and Lepine 2000), offline interpretation bias would also uniquely contribute to avoidance of offline social situations.

\section{Method}

\section{Participants and Procedure}

A total of 364 students from two universities located in [blinded for peer review] started the survey but 35 of these were excluded because they didn't complete any questionnaires $(n=10)$, provided answers to the demographic questions only $(n=11)$, or missed $>20 \%$ of the items on either the Adolescents' Interpretation and Belief Questionnaire (AIBQ) or the Multidimensional Offline and Online Peer Victimization Scale (MOOPV; $n=14$ ). In addition, 5 cases outside of the target age range ( $>25$ years) were excluded. This left a final sample of 324 students $\left(M_{\text {age }}=20.44\right.$, $S D=1.61$; age range: $18-25$ years; $20.7 \%$ male) who studied communication science $(73.5 \%)$ or psychology (26.5\%). Students were recruited through their university's participation system and completed a 20-min online survey (on the Qualtrics platform) for which they received participation credits. Participants could complete the survey from any digital device with Internet access. At the start of the survey informed consent was obtained from all individual participants in the study. Here we report on data from a selection of questionnaires included in the whole survey. The study was approved by each university's ethical committee.

\section{Materials}

\section{Online and Offline Interpretation Bias}

Online and offline interpretation bias was assessed with an extended version of the Adolescents' Interpretation and Belief Questionnaire (AIBQ; Miers et al. 2008), here termed the AIBQ 2.0. ${ }^{2}$ Five items measured the offline interpretation bias and seven ambiguous online social situations measured online interpretation bias. In line with previous interpretation bias research, the AIBQ utilizes hypothetical situations in which an ambiguous event occurs (e.g., Stopa and Clark 2000; Voncken et al. 2003). Participants are instructed to imagine that they are experiencing the situation described. Each situation is followed by a question to assess participants' interpretations (e.g., "You've invited a group of fellow students to your birthday, but a few have not yet said if they're coming. Why haven't they said something yet?"). The seven online items covered text-based communication in the social networking sites, Facebook, Twitter, and Instagram, online gaming sites, the messaging medium, WhatsApp, and the dating site MESH. The potential interaction partners ranged from good friends to online acquaintances. An example online item is "Lots of your fellow students have a Twitter account. You set up your own Twitter account and post a funny opening tweet. After a few days you only have one follower. Why do you have only one follower?" Participants rated a positive (e.g., "I just need to wait a few more days; then I will have more followers"), neutral (e.g., "There are so many Twitter accounts to follow that mine just hasn't been noticed"), and negative ("Nobody thinks my opening tweet is funny and that's why I only have one follower") interpretation of each situation on a 5-point scale ( 1 =Doesn't pop-up in my mind, $5=$ Definitely pops up in my mind). Because an interpretation bias is defined by perceptions of a negative or threatening intention (Miers et al. 2008) the negative interpretations of the online and offline social situations were used in analyses.

To check whether two separate constructs are measured by the AIBQ 2.0 a principal components factor analysis with oblimin rotation was run on the negative interpretations of the 12 online and offline items. Two factors were extracted explaining a combined $47.68 \%$ of variance; the factor loadings are shown in Supplementary Table 1. Four of the seven online items loaded strongly on the intended factor and four of the five offline items loaded strongly on the intended factor. Follow-up confirmatory factor analyses were conducted to test whether the fit of this two factor structure, each factor with four items (Table S1), was stronger than

2 The AIBQ 2.0 with 8 items is available upon request from the first author. 
the fit of a one factor structure where the eight items were expected to load on one latent interpretation bias variable. As expected, the fit for the one factor structure was insufficient, $\chi^{2}(20)=88.78, p<0.001, \mathrm{CFI}=0.89$, GFI $=0.93$, and RMSEA $=0.10$ [0.08-0.13], $p$-close $<0.001$, whereas the fit of the two factor solution was acceptable, $\chi^{2}(19)=38.98$, $p=0.004, \mathrm{CFI}=0.97, \mathrm{GFI}=0.97$, and $\mathrm{RMSEA}=0.057$ [0.031-0.082], $p$-close $=0.31 .{ }^{3}$ Consequently, all subsequent analyses were based on these two subscales, each with four negative interpretation items. Table $\mathrm{S} 2$ provides descriptive statistics of these final eight items from the AIBQ 2.0.

\section{Social Anxiety}

The Dutch translation (H. Koot \& E. Utens, unpublished) of the Social Anxiety Scale for Adolescents (La Greca and Lopez 1998) provided the measure of social anxiety. This 22 -item instrument contains 18 descriptive self-statements about social anxiety symptoms (e.g., "I worry about what others think of me") and four filler items. Respondents are asked to rate each item according to the degree to which the item "is true for you" $(1=$ not at all, $5=$ all the time $)$. The SAS-A has good psychometric properties (La Greca and Lopez 1998; Storch et al. 2004).

\section{Online and Offline Peer Victimization}

To assess how often young people experience online and offline peer victimization (PV) we used the online subscale from the Multidimensional Offline and Online Peer Victimization Scale (MOOPV; Sumter et al. 2015). This scale asks respondents how often in the past six months they have experienced particular things with peers in general, excluding the internet (10 offline items) and on the internet (10 online items). The experiences included for example being called names, being insulted, and spreading secrets and making others not like you. The questionnaire does not specify particular internet sites, such as Facebook, as the source of the victimization; the context within which online victimization could occur remains broad. Response options are (1) never, (2) once in the past six months, (3) 2-3 times in the past six months, (4) about once a month, (5) about once a week, and (6) almost every day.

\footnotetext{
3 The $p$-close indicates how well the data fit the predefined model (closeness of fit). A non-significant $p$-close indicates that there is no difference between the data and the predefined model and that the fit is acceptable.
}

\section{Online and Offline Social Avoidance Behavior}

The desire to avoid offline and online social situations was assessed with the question "Do you try to avoid this situation?" following each offline or online situation in the measure of interpretation bias. One offline situation ("Two fellow students, who are standing talking to each other, look at you") did not lend itself to asking about avoidance behavior, leaving four offline items. Response options were on a ninepoint Likert scale $(1=$ never, $5=$ sometimes, $9=$ always $)$. This way of asking about avoidance behavior has previously been employed (Miers et al. 2014).

\section{Data Analyses}

First, we performed descriptive analyses of all study variables, including all Pearson bivariate correlations. Second, to answer the study's three research questions five hierarchical regression analyses were performed. We used bootstrapping because it does not require distributional assumptions (see Descriptive Statistics section; Preacher and Hayes 2004). Significance of effects is corrected for the number of regression analyses $(p=0.01)$ and we controlled for sex and age in the first step of all regressions. Third, to explore the mediating role of interpretation bias we conducted four mediation models using the PROCESS macro v3.3 (Hayes 2018), model 4. In all four models social anxiety was entered as the independent variable, online or offline interpretation bias as the mediator, and either PV or avoidance behavior as the outcome variable. We controlled for sex, age, and offline interpretation bias in the online-models, and online interpretation bias in the offline-models. The macro uses ordinary least squares (OLS) analysis for calculating the mediation effects, and bootstrapping for calculating the confidence intervals (CI). We used bootstrap CIs based on 5000 bootstrap samples with a $95 \%$ confidence level. When the confidence intervals do not include zero, the effect is interpreted as significant. Data were analyzed with IBM SPSS, version 25.0.

\section{Results}

\section{Descriptive Statistics}

Table 1 reports the descriptive statistics for all study variables. All variables were reliable at an acceptable 0.70 level (Cortina 1993). All variables except offline and online peer victimization were normally distributed (skewness $<1$ ). Females reported significantly higher levels of social anxiety and a greater tendency to negatively interpret offline social situations than males, $F(1,322)=17.20, p<0.001$, 
Table 1 Pearson correlations, means, standard deviations, and Cronbach's alpha for all study variables $(\mathrm{N}=324)$

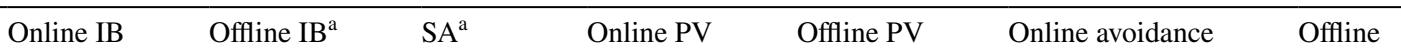

Online IB

Offline IB

SA

Online PV

$0.53 * *$

$0.42 * *$

$0.33 * *$

Offline PV

$0.30 * *$

Online avoidance

$0.27 * *$

$0.24 * *$

Offline avoidance

$0.31 * *$

$0.16^{*}$

Mean

1.97

$0.52 * *$

0.77

2.84

$S D$

0.71

0.83

0.75

$\begin{array}{ll}- & - \\ 0.35 * * & \\ 0.41^{* *} & 0.80^{* *} \\ 0.23 * * & 0.14^{\dagger} \\ 0.59 * * & 0.27 * * \\ 2.46 & 1.27 \\ 0.74 & 0.47 \\ 0.95 & 0.90\end{array}$

-
$0.17 *$
$0.28^{* *}$
1.37
0.50
0.88

$-$

$0.23 * *$

3.62

3.12

1.88

1.52

0.70

0.70

The avoidance subscales utilize the same online and offline situations as the interpretation bias subscales

$I B$ interpretation bias, $S A$ social anxiety, $P V$ peer victimization

$* p<0.01, * * p<0.001,{ }^{\dagger} p<0.05$

${ }^{a}$ Sex difference significant at $p<0.007$ (Bonferroni corrected); females reported significantly higher negative interpretation bias and social anxiety

${ }^{\mathrm{b}}$ Offline avoidance has three items

Table 2 Summary of hierarchical regression analysis predicting social anxiety

\begin{tabular}{|c|c|c|c|c|c|c|c|c|c|}
\hline \multirow[t]{3}{*}{ Variable } & \multicolumn{9}{|l|}{ Social anxiety } \\
\hline & \multicolumn{2}{|l|}{ Model 1} & \multirow[b]{2}{*}{$\beta$} & \multicolumn{3}{|l|}{ Model 2} & \multicolumn{3}{|l|}{ Model 3} \\
\hline & $B(S E)$ & $95 \% \mathrm{CI}$ & & $B(S E)$ & $95 \% \mathrm{CI}$ & $\beta$ & $B(S E)$ & $95 \% \mathrm{CI}$ & $\beta$ \\
\hline $\begin{array}{l}\text { Sex } \\
\quad(\text { female }=1)\end{array}$ & $0.31(0.10)$ & {$[0.12,0.49]$} & $0.17^{*}$ & $0.09(0.08)$ & {$[-0.05,0.25]$} & 0.05 & $0.12(0.08)$ & {$[-0.04,0.27]$} & 0.06 \\
\hline Age & $-0.10(0.03)$ & $\begin{array}{r}{[-0.15} \\
-0.06]\end{array}$ & $-0.23 * *$ & $-0.05(0.02)$ & $\begin{array}{l}{[-0.09} \\
-0.02]\end{array}$ & $-0.11^{*}$ & $-0.05(0.02)$ & $\begin{array}{l}{[-0.09} \\
-0.02]\end{array}$ & $-0.11^{*}$ \\
\hline Offline IB & & & & $0.58(0.04)$ & {$[0.50,0.65]$} & $0.65 * *$ & $0.53(0.04)$ & {$[0.44,0.61]$} & $0.59 * *$ \\
\hline Online IB & & & & & & & $0.09(0.05)$ & {$[-0.01,0.19]$} & 0.10 \\
\hline Adjusted $R^{2}$ & 0.09 & & & 0.48 & & & 0.48 & & \\
\hline $\begin{array}{l}F \text { for change } \\
\quad \text { in } R^{2}\end{array}$ & $17.42 * *$ & & & $239.39 * *$ & & & 4.16 & & \\
\hline
\end{tabular}

$I B$ interpretation bias

$* p<0.01, * * p<0.001$ (Bonferroni corrected)

$d=0.59\left[M_{\text {males }}=2.13, S D_{\text {males }}=0.67\right.$ and $M_{\text {females }}=2.54$, $\left.S D_{\text {females }}=0.73\right]$ and $F(1,322)=16.86, p<0.001$, $d=0.58\left[M_{\text {males }}=2.48, S D_{\text {males }}=0.78\right.$ and $M_{\text {females }}=2.94$, $\left.S D_{\text {females }}=0.82\right]$. The inter-correlations showed small to large positive associations ( $r$ 's ranging from 0.14 to 0.68 ) and indicate overlap between variables associated with the online and offline social environments. In terms of the control variables, age correlated negatively with social anxiety and offline interpretation bias $r=-0.27$ and $r=-0.22$, $p<0.001$; sex $($ males $=0$, females $=1)$ correlated positively with social anxiety and an offline interpretation bias $(r=0.23$ and $r=0.22, p<0.001$, respectively), and negatively with offline PV $(r=-0.15, p=0.009)$.

\section{Online Interpretation Bias and Social Anxiety}

Both online interpretation bias $(r=0.42, p<0.001)$ and offline interpretation bias $(r=0.68, p<0.001)$ correlated with social anxiety. Table 2 shows the results of the hierarchical regression analysis to examine whether an online interpretation bias uniquely predicts ${ }^{4}$ variance in social

\footnotetext{
${ }^{4}$ In the hierarchical multiple regressions the variables sex, age, social anxiety, online and offline interpretation biases are statistical predictors of the outcome variables. Hence the term 'predictor' is used in the Results section.
} 
Table 3 Summary of hierarchical regression analyses predicting (a) online peer victimization and (b) online avoidance

\begin{tabular}{|c|c|c|c|c|c|c|c|c|c|}
\hline \multirow[t]{2}{*}{ Predictor } & \multicolumn{2}{|l|}{ Model 1} & \multirow[b]{2}{*}{$\beta$} & \multicolumn{3}{|l|}{ Model 2} & \multicolumn{3}{|l|}{ Model 3} \\
\hline & $B(S E)$ & $95 \% \mathrm{CI}$ & & $B(S E)$ & $95 \% \mathrm{CI}$ & $\beta$ & $B(S E)$ & $95 \% \mathrm{CI}$ & $\beta$ \\
\hline \multicolumn{10}{|l|}{$\begin{array}{l}\text { Online peer } \\
\text { victimization }\end{array}$} \\
\hline $\begin{array}{l}\text { Sex } \\
\quad(\text { female }=1)\end{array}$ & $-0.16(0.07)$ & $\begin{array}{l}{[-0.28} \\
-0.03]\end{array}$ & -0.13 & $-0.24(0.06)$ & $\begin{array}{l}{[-0.35} \\
-0.13]\end{array}$ & $-0.21 * *$ & $-0.20(0.06)$ & $\begin{array}{l}{[-0.32} \\
-0.09]\end{array}$ & $-0.18^{*}$ \\
\hline Age & $-0.00(0.02)$ & {$[-0.03,0.02]$} & -0.01 & $0.02(0.02)$ & {$[-0.01,0.06]$} & 0.08 & $0.02(0.02)$ & {$[-0.01,0.06]$} & 0.08 \\
\hline Offline IB & & & & $0.02(0.04)$ & {$[-0.05,0.08]$} & 0.03 & $-0.04(0.04)$ & {$[-0.15,0.05]$} & -0.08 \\
\hline SA & & & & $0.25(0.05)$ & {$[0.12,0.43]$} & $0.39 * *$ & $0.23(0.05)$ & {$[0.11,0.38]$} & $0.36^{* *}$ \\
\hline Online IB & & & & & & & $0.14(0.04)$ & {$[0.02,0.27]$} & $0.23 * *$ \\
\hline $\begin{array}{l}\text { Adjusted } R^{2} / F \\
\text { for change } \\
\text { in } R^{2}\end{array}$ & $0.01 / 2.82$ & & & $0.16 / 29.55^{* *}$ & & & $0.20 / 14.55^{* *}$ & & \\
\hline \multicolumn{10}{|l|}{ Online avoidance } \\
\hline $\begin{array}{l}\text { Sex } \\
\quad(\text { female }=1)\end{array}$ & $-0.02(0.27)$ & {$[-0.55,0.49]$} & -0.00 & $-0.22(0.27)$ & {$[-0.76,0.30]$} & -0.05 & $-0.08(0.26)$ & {$[-0.60,0.42]$} & -0.02 \\
\hline Age & $0.03(0.07)$ & {$[-0.10,0.16]$} & 0.03 & $0.10(0.07)$ & {$[-0.03,0.23]$} & 0.09 & $0.11(0.07)$ & {$[-0.02,0.23]$} & 0.09 \\
\hline Offline IB & & & & $0.03(0.17)$ & {$[-0.32,0.39]$} & 0.01 & $-0.22(0.18)$ & {$[-0.59,0.17]$} & -0.10 \\
\hline SA & & & & $0.65(0.19)$ & {$[0.24,1.06]$} & $0.26^{*}$ & $0.57(0.19)$ & {$[0.17,0.98]$} & $0.22 *$ \\
\hline Online IB & & & & & & & $0.57(0.16)$ & {$[0.26,0.88]$} & $0.23 * *$ \\
\hline $\begin{array}{l}\text { Adjusted } R^{2} / F \\
\text { for change } \\
\text { in } R^{2}\end{array}$ & $-0.01 / 0.12$ & & & $0.05 / 10.56^{* *}$ & & & $0.09 / 13.55^{* *}$ & & \\
\hline
\end{tabular}

5000 bootstrap samples

$I B$ interpretation bias, $S A$ social anxiety

$* p<0.01, * * p<0.001$ (Bonferroni corrected)

anxiety, over and above sex, age, and an offline interpretation bias. The analysis showed that offline interpretation bias is a unique predictor of social anxiety, adding a significant $39 \%$ explained variance to the $9 \%$ explained by the covariates sex and age. Adding online interpretation bias to the model did not significantly increase the explained variance. Thus, online interpretation bias did not uniquely predict social anxiety (at the $p=0.01$ level) after controlling for sex, age, and an offline interpretation bias. ${ }^{5}$ In the final model, age negatively contributed to the prediction of social anxiety ( $\beta=-0.11, p=0.009)$ meaning that as age increased the reported social anxiety level decreased.

Many of the social anxiety items refer to offline social situations (e.g., being "around people", "doing something in front of others", and being "with a group of people") but not online situations, hence the social anxiety measure has more content overlap with offline than online interpretation bias. ${ }^{6}$

\footnotetext{
5 Vice-versa, if online interpretation bias is entered in the second step, after controlling for sex and age and before offline interpretation bias, the total explained variance is $25 \%$. Subsequently adding offline interpretation bias explains an additional $23 \%$.

${ }^{6}$ We thank an anonymous reviewer for making this suggestion.
}

We therefore ran a post-hoc regression analyses, exactly the same as the analysis for research question 1, except using the Fear of Negative Evaluation (FNE) subscale from the SAS-A as the dependent variable, excluding items that make reference to face-to-face situations. In this analysis, the final model (including sex and age) showed a unique contribution of online interpretation bias $(\beta=0.16, p=0.001,95 \% \mathrm{CI}$ $[0.06,0.26])$, as well as offline interpretation bias $(\beta=0.54$, $p<0.001,95 \%$ CI $[0.41,0.60])$ to FNE. Neither sex nor age were unique significant predictors.

\section{Online and Offline Interpretation Bias, Peer Victimization, and Avoidance Behavior}

Tables 3 and 4 show the results of the regression analyses employed to answer research questions (b) and (c) regarding the contribution of online and offline interpretation biases to PV and avoidance. Online interpretation bias significantly contributed to both online PV $(\beta=0.23, p<0.001)$ and online avoidance behavior $(\beta=0.23, p<0.001)$, over and above the contribution of sex, age, offline interpretation bias, and social anxiety. The total explained variance was higher for online PV (20\%) than for online avoidance (9\%). Greater online PV was predicted by being male, higher 


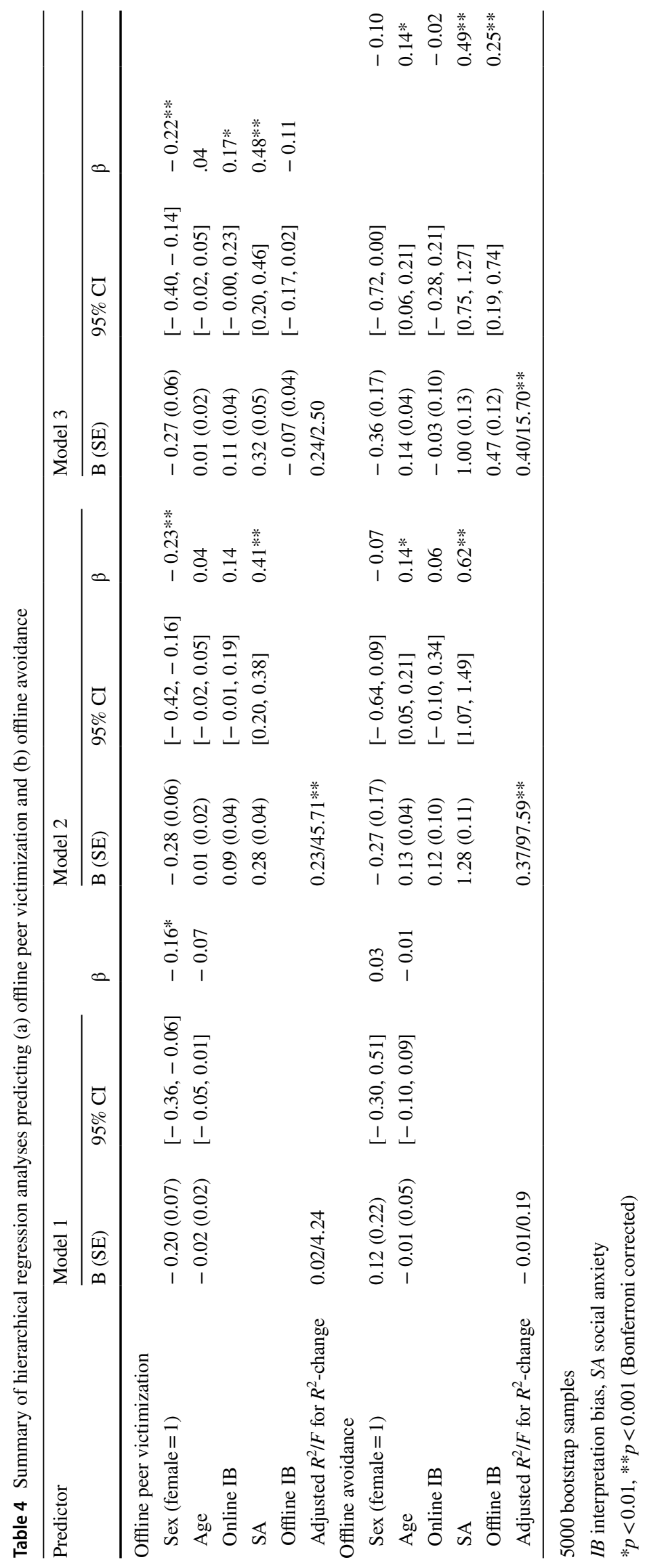


Table 5 Summary of mediation models with interpretation bias as a mediator between social anxiety and victimization or avoidance

\begin{tabular}{|c|c|c|c|c|c|c|c|c|c|}
\hline $\begin{array}{l}\text { Independent } \\
\text { variable }(X)\end{array}$ & $\begin{array}{l}\text { Mediator } \\
\text { Variable } \\
\text { (M) }\end{array}$ & $\begin{array}{l}\text { Dependent } \\
\text { variable }(\mathrm{Y})\end{array}$ & $\begin{array}{l}\text { Effect of } \\
\text { X on } \mathrm{M} \\
(a)\end{array}$ & $\begin{array}{l}\text { Effect of } \\
\mathrm{M} \text { on } \mathrm{Y} \\
(b)\end{array}$ & $\begin{array}{l}\text { Direct effect } \\
\left(c^{\prime}\right)\end{array}$ & $\begin{array}{l}\text { Indirect } \\
\text { effect } \\
(a \times b)\end{array}$ & $\begin{array}{l}95 \% \text { CI indi- } \\
\text { rect effect }\end{array}$ & $\begin{array}{l}\text { Total effect } \\
\text { (c) }\end{array}$ & $\begin{array}{l}\text { Adjusted } \mathrm{R}^{2} \\
(\%)\end{array}$ \\
\hline Social anxiety & Online IB & Online PV & $0.14^{\dagger}$ & $0.14 * *$ & $0.23 * *$ & 0.02 & {$[-0.00,0.06]$} & $0.25 * *$ & $17.09 \%$ \\
\hline Social anxiety & Online IB & $\begin{array}{l}\text { Online avoid- } \\
\text { ance }\end{array}$ & $0.14^{\dagger}$ & $0.57 * *$ & $0.57^{*}$ & 0.08 & {$[-0.01,0.19]$} & $0.65^{* *}$ & $6.28 \%$ \\
\hline Social anxiety & Offline IB & Offline PV & $0.60 * *$ & -0.07 & $0.32 * *$ & -0.04 & {$[-0.10,0.01]$} & $0.28 * *$ & $24.28 \%$ \\
\hline Social anxiety & Offline IB & $\begin{array}{l}\text { Offline avoid- } \\
\text { ance }\end{array}$ & $0.60 * *$ & $0.47 * *$ & $1.00 * *$ & $0.28^{\mathrm{a}}$ & {$[0.12,0.45]$} & $1.28 * *$ & $38.03 \%$ \\
\hline
\end{tabular}

$I B$ interpretation bias, $P V$ peer victimization

${ }^{*} p<0.01, * * p<0.001,{ }^{\dagger} p<0.05$

${ }^{\mathrm{a}}$ Indirect effect is significant at $p<0.05$

social anxiety, and a greater tendency to interpret ambiguous online situations negatively. Online avoidance behavior was predicted by both an online interpretation bias and social anxiety. Notably, an offline interpretation bias did not contribute to online PV or to online avoidance.

Offline interpretation bias uniquely contributed to offline avoidance $(\beta=0.25, p<0.001)$ but not to offline PV $(\beta=-0.11, p=0.115)$. Greater offline PV was predicted by being male, higher social anxiety levels, and a tendency to interpret online contexts negatively, together accounting for $24 \%$ of the variance. For offline avoidance a total of $40 \%$ of the variance was explained by the variables age, social anxiety, and an offline interpretation bias. Offline interpretation bias added a significant 3\% explained variance over and above social anxiety. An online interpretation bias did not uniquely contribute to avoidance in offline contexts.

\section{Mediating Role of Online and Offline Interpretation Bias}

Table 5 reports the results of the four mediation models. An online interpretation bias did not mediate the relationship between social anxiety and online PV nor between social anxiety and online avoidance. Pathway $b$ testing the effect of online interpretation bias on the outcome variables was significant and positive in both models. Nevertheless, the size of the direct effect of social anxiety on online PV and online avoidance was large and the indirect effects were not significant. As regards the covariates, the only significant effect was found in the final online PV model, where sex was a significant predictor $(B=-0.24, p<0.001,95 \%$ CIs $[-0.36,-0.12])$ showing that being male is related to greater online PV. Offline interpretation bias, sex and age were unrelated to online avoidance.

In the offline models, a significant indirect effect for offline interpretation bias was found in the relationship between social anxiety and offline avoidance $(B=0.28,95 \%$ CIs $[0.22,0.45])$, but not offline PV. Social anxiety showed significant direct effects on both offline PV and offline avoidance. In terms of the covariates, online interpretation bias was significantly related to offline $\mathrm{PV}(B=0.09, p=0.013$, $95 \%$ CIs $[0.02,0.16])$, as was $\operatorname{sex}(B=-0.28, p<0.001$, $95 \%$ CIs [ $-0.41,-0.16])$; in relation to offline avoidance, older age was related to greater avoidance $(B=0.13$, $p=0.003,95 \%$ CI $[0.04,0.22])$.

\section{Discussion}

To the best of our knowledge, this is the first study to simultaneously examine an online and offline interpretation bias in relation to social anxiety, social experiences, and behavior. First, we found that an online interpretation bias was moderately positively associated with social anxiety symptoms, yet it did not contribute unique variance to social anxiety, over and above that of offline interpretation bias. Second, overall the results showed within-context specificity in terms of the associations with social experiences and behavior. That is, after accounting for social anxiety, an online (but not offline) interpretation bias significantly contributed to self-reported peer victimization and avoidance behavior in the online context. Vice-versa, an offline (but not online) interpretation bias was uniquely associated with avoidance of offline situations, after accounting for social anxiety. An exception to this domain specificity effect was the finding that online (but not offline) interpretation bias significantly contributed to offline peer victimization. Third, exploratory mediation analyses revealed a potential explanatory role for offline interpretation bias whereby social anxiety's association with offline avoidance is mediated by an offline interpretation bias.

With regard to the first research question, our findings showed that whilst an online interpretation bias correlated positively with social anxiety, it did not have a unique contribution to social anxiety, over and above offline interpretation bias and age. The positive association between social 
anxiety and online interpretation bias therefore partly replicates, but also extends previous research (Carruthers et al. 2019; Kingsbury and Coplan 2016), by showing that social anxiety is positively related to an interpretation bias in different online contexts, such as Instagram, Facebook, and Twitter. This nonsignificant contribution of online interpretation bias to social anxiety is not in line with our expectation. However, this particular finding could be explained by measurement artifact, that is, the overlap in content of the social anxiety items and the offline interpretation bias measure, relative to online interpretation bias. In line with this suggestion, our post-hoc analyses using the Fear of Negative Evaluation items only showed a significant and unique contribution of an online interpretation bias to social anxiety. We recommend that to gain a better understanding of the relations between interpretation bias and social anxiety, future research should include parallel measures of each construct in both the online and offline context, similar to our domain-specific measures of peer victimization and avoidance behavior. Taken together with the 0.53 bivariate correlation between online and offline interpretation bias, these results tentatively suggest that online and offline interpretation bias, whilst strongly related, are not one and the same cognitive bias.

The second research question addressed the contribution of online interpretation bias to peer victimization and avoidance behavior. In line with previous research (e.g., van den Eijnden et al. 2014) social anxiety was positively related to self-reported online peer victimization. In addition, online interpretation bias made a unique positive contribution to online peer victimization. Thus, after accounting for the level of social anxiety, a young person's tendency to negatively interpret online social situations, was significantly related to a higher level of online peer victimization. A tendency to negatively perceive online social situations also significantly contributed to their self-reported tendency to avoid these online social situations. To the best of our knowledge, these results are the first to show the relationship between online interpretation bias, peer victimization, and avoidance of social situations. Moreover, online interpretation bias explains individual differences in online peer victimization and online avoidance, over and above social anxiety.

Turning to the third research question, regarding the contribution of offline interpretation bias to peer victimization and avoidance behavior, the findings were not completely in line with our expectations: offline interpretation bias uniquely contributed to avoidance behavior but not to peer victimization and online interpretation bias uniquely contributed to offline peer victimization. It is difficult to interpret why an online but not an offline interpretation bias contributed to offline peer victimization. Whilst we did not expect a cross-context association between interpretation bias and peer victimization, given the reported strong overlap between online and offline peer networks and victimization experiences (Gini et al. 2018), we may speculate that a negative online interpretation bias could indeed carry over into the offline context in the form of peer victimization. Nevertheless, this doesn't fully account for the absence of a within-context association between offline interpretation bias and peer victimization; replication is therefore required to know if this is a meaningful association. In the final models predicting offline experiences and behavior, social anxiety contributed significantly to offline peer victimization, and individual differences in avoidance were explained by social anxiety and offline interpretation bias. The positive association between social anxiety and offline peer victimization adds to a large body of research showing the perceived negative treatment of socially anxious youth by their age peers (e.g., Gini et al. 2018; Siegel et al. 2009; van den Eijnden et al. 2014). In terms of young people reporting that they try to avoid face-to-face social situations, the positive relationship with social anxiety has previously been reported (e.g., Miers et al. 2014). However, to the best of our knowledge, this is the first study to show a direct association between interpretation bias and avoidance in offline contexts. The current study therefore adds to previous research by showing that, in addition to the cognitive process of post-event processing (Miers et al. 2014), young people who have a negative interpretation bias are likely to avoid social situations. This avoidance behavior can have detrimental consequences for their social relationships and skills and, in turn, potentially worsen their social anxiety symptoms.

Finally, we explored whether interpretation biases mediated the associations between social anxiety and both peer victimization and avoidance. These analyses showed that although social anxiety was related to both peer victimization and avoidance in online and offline contexts, these relationships were not mediated by an online interpretation bias. Although this bias did make an independent contribution to explaining individual differences in these variables, our findings imply that the reason why socially anxious young people experience peer victimization in, and avoid, online situations cannot be attributed to a tendency to negatively interpret online social situations. This suggests that other variables are more likely to explain peer victimization of socially anxious youth in online situations, and socially anxious youth's tendency to avoid these online social situations. There is little research addressing why people with social anxiety are victimized in online settings where awkward behavior, keeping very still for example (Gray et al. 2019), might be less detectable due to limited visual cues. However, it is still possible that the way socially anxious people use social media can trigger more negative responses. For example, it has been suggested that when actively using social media, socially anxious individuals post material that 
is self-disparaging in nature (Leigh and Clark 2018). Such negative and critical material may subsequently elicit derogatory and exclusionary responses from their online peers. In terms of explaining the social anxiety-online avoidance relation, it could be due to the experience of peer victimization, or due to the heightened anxiety experienced when using social media (Carruthers et al. 2019). These proposed explanatory mechanisms clearly need to be tested in further research, ideally using a longitudinal design in order to address temporal ordering.

Although we did not find support for an online interpretation bias as an underlying mechanism, we found partial support for an offline interpretation bias as an underlying mechanism. That is, the offline interpretation bias mediated the relationship between social anxiety and offline avoidance, but not between social anxiety and offline peer victimization. The finding that offline interpretation bias explains the relation between social anxiety and avoidance of offline situations indicates that a motivation to avoid face-to-face social situations is, on the one hand, driven directly by social anxiety itself, and on the other hand, driven by a tendency to perceive an offline social situation as negative or threatening. Indeed, it may be a defense mechanism or safety behavior to avoid situations that are interpreted as threatening, as this avoidance could prevent rejection experiences. In order to corroborate this mediation result, future research could test this sequence-social anxiety-offline interpretation biasavoidance of social situations - using a longitudinal design and an objective measure of avoidance.

\section{Clinical Implications}

The findings from this study are clinically useful as they point to ways to optimize cognitive behavioral interventions for social anxiety. For example, given that on- and offline interpretation bias are related but separate constructs that are both relevant to social anxiety, it may be valuable to target negative social beliefs in both settings during treatment. This could be done by carrying out behavioral experiments on social media platforms as well as in traditional contexts. A patient could be encouraged to test out a belief such as "I am boring" online. A behavioral experiment might test the prediction that "they only left a comment to be nice, they don't really like me. If I message them back with whatever comes to mind, they will not respond" and involve engaging in an online interaction, without preparation, to find out how the other person responds.

In addition, surveys could be used to test negative beliefs in online situations. These might focus on helping a patient to discover that ambiguity is typical of online interactions, rather than specific to them personally, and that there are many possible explanations for ambiguous or even mildly negative comments or responses online. A survey sent out to a group of people could begin: "Do you ever forget to reply to messages online? Are your messages ever left without a reply? How common do you think this is? What might be the reasons for this? When you don't reply to someone, is it usually because you dislike them?" and so on. These questions will help the patient to discover the broad range of reasons for ambiguity in social media and provide them with the confidence to carry out behavioral experiments online.

\section{Limitations}

The present study has some limitations that should be noted. First, the cross-sectional design means that we cannot conclude that an online or offline interpretation bias lead to more social anxiety symptoms and negative online experiences and behavior, or vice-versa. For example, having negative experiences with peers either offline or online could be a contributing factor to the development of a negative bias, and subsequently social anxiety. In this case, an individual's bias might actually reflect a kernel of truth (Miers et al. 2011). Research employing a longitudinal or experimental design is required to tease apart causality effects, and consider transactional relationships between the interpretation bias, social anxiety, and peer victimization.

Second, all measures were self-report and interpretation bias was measured through hypothetical vignettes (or “ambiguous scenarios test”; Schoth and Liossi 2017). This means that the responses might be influenced by social desirability and the chance of finding significant relationships is inflated. In addition, responses to hypothetical vignettes with pre-determined interpretations may not reflect a young person's actual initial, personal interpretation of the situation and responses may be influenced by verbal fluency level (Schoth and Liossi 2017). To overcome some of these issues future research should include and compare direct (e.g., participant response on emotion recognition task) and indirect (e.g., participant performance behavior on an incidental learning task) measures of interpretation bias, ideally with the same stimuli, and in the same population (Schoth and Liossi 2017). Further, using different informants such as parents and teachers for social anxiety and avoidance behavior, and peer ratings for victimization, could bolster the current findings. For example, a young person's self-report of peer victimization may itself be influenced by socially anxious feelings or interpretation bias rather than an accurate reflection of whether peer exclusion and rejection occurred (Lansu et al. 2017), highlighting the importance of using different sources to assess relevant constructs.

Third, we caution that the current findings cannot necessarily be generalized to younger age groups. A recent review of the relation between offline interpretation bias and anxiety in children and adolescents showed that the strength of this 
relationship increases with increasing age (Stuijfzand et al. 2018). It is therefore possible that the relative contributions of online and offline interpretation bias to social anxiety in younger populations would be different to those reported here.

\section{Conclusion}

Social media and online social situations have become an ubiquitous part of young people's social lives. For the first time, the current study investigated the relative importance of the interpretation bias in relation to online and offline social situations, in terms of their associations with social anxiety, peer victimization, and avoidance. The current study's findings add to existing research (Carruthers et al. 2019; Kingsbury and Coplan 2016) attesting to the importance of studying an online interpretation bias in relation to social anxiety in young people. It is associated with higher levels of social anxiety and does not appear to be a mere proxy for offline interpretation bias. Moreover, we found evidence for within-context specificity in terms of the unique contribution of online interpretation bias to online peer victimization and avoidance, over and above variance accounted for by social anxiety. A better understanding of whether online interpretation bias, like its offline counterpart, is a key characteristic of anxiety disorders among young people is recommended, as this could open up new intervention possibilities through training to lessen an online negative interpretation bias.

\section{Compliance with Ethical Standards}

Conflict of Interest Anne C. Miers, Sindy R. Sumter, David M. Clark, and Eleanor Leigh declare that they have no conflict of interest.

Ethical Approval All procedures performed in studies involving human participants were in accordance with the ethical standards of the institutional and/or national research committee and with the 1964 Helsinki declaration and its later amendments or comparable ethical standards.

Animal Rights This article does not contain any studies with animals performed by any of the authors.

Informed Consent Informed consent was obtained from all individual participants included in the study.

Open Access This article is licensed under a Creative Commons Attribution 4.0 International License, which permits use, sharing, adaptation, distribution and reproduction in any medium or format, as long as you give appropriate credit to the original author(s) and the source, provide a link to the Creative Commons licence, and indicate if changes were made. The images or other third party material in this article are included in the article's Creative Commons licence, unless indicated otherwise in a credit line to the material. If material is not included in the article's Creative Commons licence and your intended use is not permitted by statutory regulation or exceeds the permitted use, you will need to obtain permission directly from the copyright holder. To view a copy of this licence, visit http://creativecommons.org/licenses/by/4.0/.

\section{References}

Alden, L. E., \& Taylor, C. T. (2004). Interpersonal processes in social phobia. Clinical Psychology Review, 24, 857-882. https://doi. org/10.1016/j.cpr.2004.07.006.

Alt, D. (2015). College students' academic motivation, media engagement and fear of missing out. Computers in Human Behavior, 49, 111-119. https://doi.org/10.1016/j.chb.2015.02.057.

Amin, N., Foa, E. B., \& Coles, M. E. (1998). Negative interpretation bias in social phobia. Behaviour Research and Therapy, 36, 945-957. https://doi.org/10.1016/S0005-7967(98)00060-6.

Carruthers, S. E., Warnock-Parkes, E. L., \& Clark, D. M. (2019). Accessing social media: Help or hindrance for people with social anxiety? Journal of Experimental Psychopathology, 10, 1-11.

Clark, D. M., \& Wells, A. (1995). A cognitive model of social phobia. In R. G. Heimberg, M. R. Liebowitz, D. A. Hope, \& F. R. Schneier (Eds.), Social phobia: Diagnosis, assessment, and treatment (Vol. 41, pp. 69-93). New York: The Guildford Press.

Cortina, J. M. (1993). What is coefficient alpha? An examination of theory and applications. Journal of applied psychology, 78(1), 98.

Coyne, S. M., Padilla-Walker, L. M., \& Howard, E. (2013). Emerging in a digital world: A decade review of media use, effects, and gratifications in emerging adulthood. Emerging Adulthood, 1(2), 125-137. https://doi.org/10.1177/2167696813479782.

Daft, R. L., \& Lengel, R. H. (1986). Organizational information requirements, media richness and structural design. Management Science, 32, 554-571. https://doi.org/10.1287/mnsc.32.5.554.

Dempsey, A. G., Sulkowski, M. L., Nichols, R., \& Storch, E. A. (2009). Differences between peer victimization in cyber and physical settings and associated psychosocial adjustment in early adolescence. Psychology in the Schools, 46, 962-972.

Gini, G., Card, N. A., \& Pozzoli, T. (2018). A meta-analysis of the differential relations of traditional and cyber-victimization with internalizing problems. Aggressive Behavior, 44, 185-198. https ://doi.org/10.1002/ab.21742.

Gosling, S. D., Gaddis, S., \& Vazire, S. (2008). First impressions based on the environments we create and inhabit. First impressions (pp. 334-356). New York, NY: Guilford Press.

Gray, E., Beierl, E. T., \& Clark, D. M. (2019). Sub-types of safety behaviours and their effects on social anxiety disorder. PLOS ONE. https://doi.org/10.1371/journal.pone.0223165.

Gros, D. F., Gros, K. S., \& Simms, L. J. (2010). Relations between anxiety symptoms and relational aggression and victimization in emerging adults. Cognitive Therapy and Research, 34(2), 134143. https://doi.org/10.1007/s10608-009-9236-z.

Hayes, A. F. (2018). Introduction to mediation, moderation, and conditional process analysis: A regression-based approach. New York: The Guilford Press.

Heinrichs, N., \& Hofmann, S. G. (2001). Information processing in social phobia: A critical review. Clinical Psychology Review, 21, 751-770. https://doi.org/10.1016/S0272-7358(00)00067-2.

Hoglund, W. L., \& Leadbeater, B. J. (2007). Managing threat: Do social-cognitive processes mediate the link between peer victimization and adjustment problems in early adolescence? Journal of Research on Adolescence, 17(3), 525-540. https://doi.org/10.11 11/j.1532-7795.2007.00533.x.

Joinson, A. N. (2001). Self-disclosure in computer-mediated communication: The role of self-awareness and visual anonymity. 
European journal of social psychology, 31, 177-192. https://doi. org/10.1002/ejsp.36.

Kingsbury, M., \& Coplan, R. J. (2016). RU mad @ me? Social anxiety and interpretation of ambiguous text messages. Computers in Human Behavior, 54, 368-379. https://doi.org/10.1016/j. chb.2015.08.032.

Kloosterman, R., \& van Beuningen, J. (2015). Jongeren over sociale media. Den Haag, The Netherlands: CBS.

Kruger, J., Epley, N., Parker, J., \& Ng, Z. W. (2005). Egocentrism over e-mail: Can we communicate as well as we think? Journal of Personality and Social Psychology, 89, 925-936. https://doi. org/10.1037/0022-3514.89.6.925.

La Greca, A. M., \& Lopez, N. (1998). Social anxiety among adolescents: Linkages with peer relations and friendships. Journal of Abnormal Child Psychology, 26, 83-94. https://doi. org/10.1023/A:1022684520514.

Lansu, T. A., van Noorden, T. H., \& Deutz, M. H. (2017). How children's victimization relates to distorted versus sensitive social cognition: Perception, mood, and need fulfillment in response to Cyberball inclusion and exclusion. Journal of Experimental Child Psychology, 154, 131-145. https://doi.org/10.1016/j. jecp.2016.10.012.

Lee, B. W., \& Stapinski, L. A. (2012). Seeking safety on the internet: Relationship between social anxiety and problematic internet use. Journal of Anxiety Disorders, 26, 197-205. https://doi. org/10.1016/j.janxdis.2011.11.001.

Leigh, E., \& Clark, D. M. (2018). Understanding social anxiety disorder in adolescents and improving treatment outcomes: Applying the cognitive model of Clark and Wells (1995). Clinical Child and Family Psychology Review, 21, 388-414. https://doi.org/10.1007/ s10567-018-0258-5.

McLellan, L. F., Alfano, C. A., \& Hudson, J. L. (2015). Cognitionfocused interventions for social anxiety disorder among adolescents. In K. Ranta, A. M. La Greca, L. Garcia-Lopez, \& M. Marttunen (Eds.), Social anxiety and phobia in adolescents (pp. 225-250). New York: Springer.

Miers, A. C., Blöte, A. W., Bögels, S. M., \& Westenberg, P. M. (2008). Interpretation bias and social anxiety in adolescents. Journal of Anxiety Disorders, 22, 1462-1471. https://doi.org/10.1016/j.janxd is.2008.02.010.

Miers, A. C., Blöte, A. W., de Rooij, M., Bokhorst, C. L., \& Westenberg, P. M. (2013). Trajectories of social anxiety during adolescence and relations with cognition, social competence, and temperament. Journal of Abnormal Child Psychology, 41, 97-110. https://doi.org/10.1007/s10802-012-9651-6.

Miers, A. C., Blöte, A. W., Heyne, D. A., \& Westenberg, P. M. (2014). Developmental pathways of social avoidance across adolescence: The role of social anxiety and negative cognition. Journal of Anxiety Disorders, 28, 787-794. https://doi.org/10.1016/j.janxd is.2014.09.008.

Miers, A. C., Blöte, A. W., \& Westenberg, P. M. (2011). Negative social cognitions in socially anxious youth: Distorted reality or a kernel of truth? Journal of Child and Family Studies, 20, 214 223. https://doi.org/10.1007/s10826-010-9423-2.

Musa, C. Z., \& Lepine, J. P. (2000). Cognitive aspects of social phobia: A review of theories and experimental research. European Psychiatry, 15, 59-66. https://doi.org/10.1016/s0924-9338(00)00210-8.

Perren, S., Ettekal, I., \& Ladd, G. (2013). The impact of peer victimization on later maladjustment: Mediating and moderating effects of hostile and self-blaming attributions. Journal of Child Psychology and Psychiatry, 54(1), 46-55. https://doi.org/10.111 1/j.1469-7610.2012.02618.x.

Preacher, K. J., \& Hayes, A. F. (2004). SPSS and SAS procedures for estimating indirect effects in simple mediation models. Behavior Research Methods, Instruments, \& Computers, 36(4), 717-731. https://doi.org/10.3758/BF03206553.
Prinstein, M. J., Cheah, C. S., \& Guyer, A. E. (2005). Peer victimization, cue interpretation, and internalizing symptoms: Preliminary concurrent and longitudinal findings for children and adolescents. Journal of Clinical Child and Adolescent Psychology, 34, 11-24. https://doi.org/10.1207/s15374424jccp3401_2.

Prizant-Passal, S., Shechner, T., \& Aderka, I. M. (2016). Social anxiety and internet use-A meta-analysis: What do we know? What are we missing? Computers in Human Behavior, 62, 221-229. https ://doi.org/10.1016/j.chb.2016.04.003.

Rapee, R. M., \& Heimberg, R. G. (1997). A cognitive-behavioral model of anxiety in social phobia. Behaviour Research and Therapy, 35(8), 741-756.

Riordan, M. A., \& Kreuz, R. J. (2010). Cues in computer-mediated communication: A corpus analysis. Computers in Human Behavior, 26, 1806-1817. https://doi.org/10.1016/j.chb.2010.07.008.

Schoth, D. E., \& Liossi, C. (2016). Biased interpretation of ambiguous information in patients with chronic pain: A systematic review and meta-analysis of current studies. Health Psychology, 35(9), 944. https://doi.org/10.1037/hea0000342.

Schoth, D. E., \& Liossi, C. (2017). A systematic review of experimental paradigms for exploring biased interpretation of ambiguous information with emotional and neutral associations. Frontiers in Psychology, 8, 171. https://doi.org/10.3389/fpsyg.2017.00171.

Siegel, R. S., La Greca, A. M., \& Harrison, H. M. (2009). Peer victimization and social anxiety in adolescents: Prospective and reciprocal relationships. Journal of Youth and Adolescence, 38, 1096-1109. https://doi.org/10.1007/s10964-009-9392-1.

Stopa, L., \& Clark, D. M. (2000). Social phobia and interpretation of social events. Behaviour Research and Therapy, 38, 273-283. https://doi.org/10.1016/S0005-7967(99)00043-1.

Storch, E. A., Masia-Warner, C., Dent, H. C., Roberti, J. W., \& Fisher, P. H. (2004). Psychometric evaluation of the Social Anxiety Scale for Adolescents and the Social Phobia and Anxiety Inventory for Children: Construct validity and normative data. Journal of Anxiety Disorders, 18, 665-679. https://doi.org/10.1007/s1080 2-007-9099-2.

Stuijfzand, S., Creswell, C., Field, A. P., Pearcey, S., \& Dodd, H. (2018). Research review: Is anxiety associated with negative interpretations of ambiguity in children and adolescents? A systematic review and meta-analysis. Journal of Child Psychology and Psychiatry, 59(11), 1127-1142. https://doi.org/10.1111/jcpp.12822.

Sumter, S. R., Valkenburg, P. M., Baumgartner, S. E., Peter, J., \& van der Hof, S. (2015). Development and validation of the Multidimensional Offline and Online Peer Victimization Scale. Computers in Human Behavior, 46, 114-122. https://doi.org/10.1016/j. chb.2014.12.042.

Valkenburg, P. M., \& Peter, J. (2011). Online communication among adolescents: An integrated model of its attraction, opportunities, and risks. Journal of Adolescent Health, 48, 121-127. https://doi. org/10.1016/j.jadohealth.2010.08.020.

Valkenburg, P. M., Peter, J., \& Walther, J. B. (2016). Media effects: Theory and research. Annual Review of Psychology, 67, 315-338. https://doi.org/10.1146/annurev-psych-122414-033608.

van den Eijnden, R., Vermulst, A., van Rooij, A. J., Scholte, R., \& van de Mheen, D. (2014). The bidirectional relationships between online victimization and psychosocial problems in adolescents: A comparison with real-life victimization. Journal of Youth and Adolescence, 43, 790-802. https://doi.org/10.1007/s1096 4-013-0003-9.

Voncken, M. J., Bögels, S. M., \& de Vries, K. (2003). Interpretation and judgmental biases in social phobia. Behaviour Research and Therapy, 41, 1481-1488. https://doi.org/10.1016/S0005 -7967(03)00143-8.

Walther, J. B. (2011). Theories of computer-mediated communication and interpersonal relations. The Handbook of Interpersonal Communication, 4, 443-479. 
Weidman, A. C., Fernandez, K. C., Levinson, C. A., Augustine, A. A., Larsen, R. J., \& Rodebaugh, T. L. (2012). Compensatory internet use among individuals higher in social anxiety and its implications for well-being. Personality and Individual Differences, 53(3), 191-195. https://doi.org/10.1016/j.paid.2012.03.003.

Weidman, A. C., \& Levinson, C. A. (2015). I'm still socially anxious online: Offline relationship impairment characterizing social anxiety manifests and is accurately perceived in online social networking profiles. Computers in Human Behavior, 49, 12-19. https://doi.org/10.1016/j.chb.2014.12.045.

Publisher's Note Springer Nature remains neutral with regard to jurisdictional claims in published maps and institutional affiliations. 